\title{
The Impact of Third Party Payment on Urban Residents' Clothing Consumption
}

\author{
Hongxuan Li, Chenggang $\mathrm{Li}^{*}$ \\ Business School, Beijing Institute of Fashion Technology, Beijing, China \\ Email: *ccid205@126.com
}

How to cite this paper: $\mathrm{Li}, \mathrm{H} . \mathrm{X} ., \mathrm{Li}, \mathrm{C}$. G. (2021). The Impact of Third Party Payment on Urban Residents' Clothing Consumption. Theoretical Economics Letters, 11, 1183-1191.

https://doi.org/10.4236/tel.2021.116075

Received: November 6, 2021

Accepted: December 14, 2021

Published: December 17, 2021

Copyright $\odot 2021$ by author(s) and Scientific Research Publishing Inc. This work is licensed under the Creative Commons Attribution International License (CC BY 4.0).

http://creativecommons.org/licenses/by/4.0/

(c) (i) Open Access

\begin{abstract}
In recent years, with the progress and development of Internet information technology, the third-party payment platform has gradually sprung up, people's life has been greatly facilitated, and the payment method has also been changed. This paper mainly explores the impact of third-party payment on urban residents' clothing consumption and makes a regression analysis on the time series data of China's urban residents' clothing consumption expenditure, the scale of third-party payment and the per capita disposable income of urban residents from 2004 to 2019 by using Eviews software. The results show that there is a long-term and stable equilibrium relationship between urban residents' clothing consumption expenditure, urban residents' per capita disposable income and the scale of third-party payment. The consumption of urban residents starts from the pursuit of quantity and quality. The expansion of the scale of third-party payment can indeed promote the consumption of clothing by urban residents, which is conducive to expanding domestic demand, driving market circulation and improving the industrial structure.
\end{abstract}

\section{Keywords}

Third-Party Payment, Clothing Consumption, Regression

\section{Introduction}

With the accelerated development of the Internet era and the rapid growth of the scale of third-party payment transactions, compared with the traditional payment mode, it has greatly promoted people's consumption power, not only saving transaction costs and more convenient operation but also protecting the rights and interests of both parties. People can't live without clothing, food,

${ }^{\star}$ Corresponding author. 
shelter and transportation. Among the four, clothing comes first. China is a "country of etiquette", and clothing is the embodiment of people's spiritual outlook. Whether residents buy clothes in physical stores or online, they are inseparable from third-party payment. With the improvement of China's urbanization level, the continuous increase of urban population and the popularity of third-party payment, it is of great significance to tap the consumption potential of urban residents. This paper first analyzes the factors affecting urban residents' clothing consumption, then focuses on the impact of the scale of third-party payment on urban residents' consumption expenditure, and takes the per capita disposable income of urban residents as one of the explanatory variables. Stimulating urban residents' clothing consumption is of great significance to expand domestic demand, drive market circulation, improve industrial structure chain, create a good social atmosphere and carry forward Chinese culture.

\section{Literature Review}

By combing the literature, there are the following research viewpoints and directions.

The first is the analysis of influencing factors of urban residents' consumption. For example, An na and Liu Xiumei selected the per capita GDP, per capita income of urban households and per capita disposable income of urban households in Shandong Province from 1981 to 2018 to study the main factors affecting the consumption level of urban residents in Shandong Province (An \& Liu, 2021). Ge Nan, Zhang Kexin and Hao Zixu selected the time series data of consumption expenditure, disposable income and GDP of urban residents. The analysis shows that there is a long-term equilibrium relationship between urban residents' disposable income and GDP on urban residents' consumption expenditure (Ge et al., 2020). According to the relationship between residents' textile and clothing consumption level and residents' income level, Sun mengrou made a quantitative analysis from three aspects: national residents, urban residents and rural residents, and concluded that there is a long-term equilibrium relationship between residents' textile and clothing consumption level and income level in China (Sun, 2016).

The second is the impact of third-party payment on Residents' consumption. For example, Zhou Liangxin used OLS regression and two-stage least square method to study. The results show that in China's economically developed areas, the impact of third-party payment on the growth of residents' consumption is relatively significant (Zhou, 2021). Wang Xiaoyan thinks that the payment platform represented by Alipay and WeChat provides residents' consumption motivation, and also greatly improves the consumption amount of residents by 5 from the data (Hu \& Wang, 2017). Lv Jianli used the dynamic time series model to empirically analyze the relationship between Chinese residents' online shopping clothing consumption, per capita disposable income and the scale of third-party payment (Lv, 2017). 
The third is the research on consumption structure and consumption psychology of third-party payment. For example, wu Sheng studied the impact of third-party payment on family structure. The results show that third-party payment significantly increases the proportion of family enjoyment consumption, thus promoting the upgrading of family consumption structure (Wu, 2021). Hua Yunrou, Yu Hailan believed that college students are the most influential group of mobile payment, and discussed the influencing factors of this group's consumption behavior (Hua \& Yu, 2018).

To sum up, in the previous literature on the impact of third-party payment on Residents' consumption, there is not much analysis on the impact of the use of third-party payment in an industry. The factors affecting urban residents' consumption include disposable income, price index, Engel coefficient, GDP, medical care, and so on. This paper mainly studies the impact of third-party payment and per capita disposable income of urban residents on urban residents' clothing consumption and then finds out their relationship, so as to promote the sustainable growth of urban residents' clothing consumption.

\section{Development Status of Clothing Consumption of Urban Residents in China}

\subsection{Analysis on Influencing Factors of Urban Residents' Clothing Consumption}

At present, China is the largest clothing production and consumption country in the world. Clothing consumption has always been an important component of people's daily life and a necessity to maintain life. Clothing consumption is more representative of urban residents. The factors affecting clothing consumption of urban residents are as follows:

First, when urban residents choose clothing for purchase, it reflects a series of psychological feelings and selection process of residents' clothing quality, consciousness, form and selection. Therefore, it is largely affected by the quality, price and subjective factors of clothing products.

Second, the clothing consumption of urban residents is related to the per capita disposable income and GDP of urban residents. When the disposable income is higher, people are usually more willing to consume and pursue the quality of life. Consumption is a part of GDP. When GDP grows steadily, prices rise moderately. When GDP grows too fast, inflation will lead to accelerated price rise. When GDP slows down, prices may fall by Chen et al. (2021).

Third, with the advent of the era of science and technology and the rapid development of the Internet, the means and methods of payment have brought convenience to residents. People can carry out a series of activities such as shopping, ordering takeout and buying medicine online. Going out to scan the code has become a way of life. People's daily travel is closely related to third-party payment, which has a great impact on Residents' clothing consumption (Zhang, 2020).

Fourth, China has a vast territory and many kinds of ethnic groups. All ethnic 
groups have their own national customs. Clothing style, cultural aesthetics and customs will have a certain impact on clothing consumption. This paper does not consider the impact of subjective factors, regional factors, cultural factors and other indicators on Residents' clothing consumption, mainly studies the impact of third-party payment and per capita disposable income of urban residents on urban residents' clothing consumption, and tries to build a model.

\subsection{Analysis on Clothing Consumption Trend of Urban Residents}

On the one hand, with the increase of China's population, the continuous development of China's economy and the continuous improvement of residents' consumption level and ability, the third-party payment, as the entrance of the Internet economy, also meets the growing diversified needs of users under the background of consumption upgrading. Urban residents are ahead of rural residents in terms of consumption level, consumption ability and consumption concept. Compared with rural residents, urban residents' clothing consumption is still the main force of national residents' clothing consumption. With the improvement of living standards, clothing consumption, as an important part of people's living consumption, will continue to increase, But the degree of increase will rise slowly (Wen, 2019). Although the sales volume of urban residents' clothing began to decline from 2004 to 2019, the overall consumption of urban residents' clothing still showed an upward trend. According to the data reported by the National Bureau of statistics, there were 54.06 billion pieces in 2018, a decrease of $24.8 \%$ compared with 71.91 billion pieces in 2017 . The price rise is the main reason for the decline of clothing sales, but clothing consumption continues to rise, indicating that China's residents' clothing consumption trend began to pursue high quality from the pursuit of quantity.

On the other hand, Novel coronavirus pneumonia, which was affected by the outbreak of new crown pneumonia in 2020, has been greatly impacted by the impact of the new crown pneumonia epidemic. The consumption level of the residents has been reduced. This article only refers to the data for 2004-2019 years. At the same time, the epidemic also accelerates the industry to embrace the development of the digital age. With the normalization of epidemic control, China's policy of promoting consumption has achieved remarkable results. Residents' consumption has gradually returned to the development track of consumption upgrading, showing a steady recovery and positive development trend.

\subsection{Analysis on the Development Status of Third-Party Payment}

Third-party payment refers to an online payment mode in which an independent institution with a certain strength and reputation guarantee facilitates transactions between both parties through docking with UnionPay or online Federation. At present, China's domestic third-party payment products are mainly PayPal, La Carla, Alipay, remittance world, Sheng Fu Tong, Yi Bao payment, online banking online, state pay treasure, ring fast payment, converging 
payment, government UnionPay payment.

Advantages of third-party payment: third-party payment facilitates online transactions; It can reduce the operation cost of enterprises; It can save the cost of gateway development; It can record the transactions of both parties in detail to prevent both parties from possible repudiation of the transaction. Disadvantages of third-party payment: due to the incompleteness of the law, the security of third-party payment cannot be well guaranteed, and the integrity risk of logistics activities independent of the network still exists.

Since 2004, third-party payment has gradually developed. So far, the development of third-party payment business has gradually matured, and the transaction volume in the industry market has increased rapidly, maintaining a state of continuous profitability. Since 2010, under the influence of different driving forces in different periods such as online shopping, social red envelope and offline code scanning payment, the transaction scale of third-party payment has experienced rapid development, as shown in Figure 1. From the perspective of future development trend, the new third-party payment will be constantly updated to fully ensure the safety of funds and provide more convenient and fast services for businesses and consumers. The scale of China's third-party payment transaction market is expected to continue to grow (Xing \& Zhang, 2019). It is predicted that the scale of China's third-party payment transaction is expected to reach 311.7 trillion yuan by 2021. The data comes from the Research Report on the third-party payment industry in 2021.

\section{Research on the Impact of Third-Party Payment on Urban Residents' Clothing Consumption}

With the advent of the Internet era and the continuous development of China's economy, the consumption level and ability of urban residents have been continuously improved. As the entrance of the Internet economy, third-party payment has become the mainstream payment method, which not only meets the growing



Figure 1. Scale of mobile payment transactions from 2014 to 2019 (Data source: public data sorting). 
diversified needs of urban residents under the background of consumption upgrading and to the recognition of more and more consumers (Xie, 2019).

\subsection{Variable Selection}

According to literature review and Keynesian macroeconomic theory, it is considered that residents' consumption demand is determined by their income, and there is a certain relationship between the two consumptions as a function of income. Therefore, due to the impact of the epidemic in 2020, the explanatory variable selected in this paper is the per capita disposable income of urban residents from 2004 to 2019 to reflect the income of urban residents. The third-party payment scale data is taken as the sample data, and the explanatory variable is the clothing consumption expenditure of urban residents. The third-party payment scale data comes from the data sorted out by iResearch consulting and prospective industry research institute. The per capita disposable income of urban residents and clothing consumption expenditure of urban residents come from the data sorted out by the National Bureau of statistics and prospective industry research institute.

\subsection{Model Establishment}

The established sample regression model is:

$$
Y=\alpha X+\beta T+E
$$

where $Y$ represents the clothing consumption expenditure of urban residents, $X$ represents the per capita disposable income of urban residents, $T$ represents the scale of third-party payment, and e represents the remaining items. The following assumptions are made for the model:

Hypothesis 1 (H1): the per capita disposable income of urban residents has a positive impact on the clothing consumption expenditure of urban residents.

Hypothesis 2 (H2): the scale of third-party payment has a positive impact on the clothing consumption expenditure of urban residents.

\subsection{Regression Analysis}

1) $\mathrm{ADF}$ stationarity test

In order to avoid regression, the stationarity test is carried out on the original time series data. The test results of each variable are shown in Table 1.

The above results $\mathrm{D}(\mathrm{Y}), \mathrm{D}(\mathrm{X})$ and $\mathrm{D}(\mathrm{T})$ are the first-order difference of variables $Y, X$ and $T$ respectively. The original data of time series $Y, X$ and $T$ are non-stationary, but they are stable after the first-order difference, that is, they are the first-order single integration series. Therefore, the cointegration relationship among urban residents' clothing consumption expenditure, urban residents' per capita disposable income and third-party payment can be further tested.

2) Cointegration test

The least-square method is used for regression analysis to obtain the cointe- 
gration regression equation, as shown in Figure 2.

$$
\begin{gathered}
Y=-608.6766+0.441171 X+0.000211 T+E \\
P=(0.0000) * * *(0.0399) * *(0.0006) * * *
\end{gathered}
$$

The stationarity test of residual e is carried out, and the test results are shown in Table 2.

The above is an attempt to study the model of third-party payment scale and per capita disposable income of urban residents on clothing consumption expenditure of urban residents. From the test results, if hypothesis 1 (H1) and hypothesis $2(\mathrm{H} 2)$ are true, the scale of third-party payment and the per capita disposable income of urban residents have a positive impact on the clothing consumption expenditure of urban residents. When other conditions remain unchanged, that is, for every 1 yuan increase in the per capita disposable income of urban residents, the clothing consumption expenditure of urban residents will increase by $44,117.1$ million yuan; for every 100 million yuan increase in the

Table 1. ADF test results.

\begin{tabular}{ccccc}
$\begin{array}{c}\text { Variable } \\
\text { name }\end{array}$ & ADF statistics & $\begin{array}{c}5 \% \text { critical } \\
\text { value }\end{array}$ & $\begin{array}{c}\text { 10\% critical } \\
\text { value }\end{array}$ & Conclusion \\
\hline$Y$ & 3.268132 & -3.875302 & -3.38833 & Nonstationary \\
$X$ & -1.749808 & -3.759743 & -3.32497 & Nonstationary \\
$T$ & 3.171568 & -3.875302 & -3.38833 & Nonstationary \\
D (Y) & -4.391426 & -3.875302 & -3.38833 & stable \\
D (X) & -3.834624 & -3.791172 & -3.34225 & stable \\
D (T) & -3.834624 & -3.791172 & -3.34225 & stable \\
\hline \hline Variable & & & & Prob. \\
\hline \hline
\end{tabular}

Figure 2. Regression results.

Table 2. Residual ADF test results.

\begin{tabular}{cccccc}
\hline $\begin{array}{c}\text { Residual } \\
\text { sequence }\end{array}$ & ADF test value & $\begin{array}{c}5 \% \text { critical } \\
\text { value }\end{array}$ & $\begin{array}{c}10 \% \text { critical } \\
\text { value }\end{array}$ & $P$ value & conclusion \\
\hline E & -4.542499 & -3.759743 & -3.324976 & 0.0137 & stable \\
\hline
\end{tabular}


scale of third-party payment, the clothing consumption expenditure of urban residents will increase by 21 thousand and 100 yuan. From 2004 to 2019, there is a cointegration relationship between China's urban residents' clothing consumption expenditure, urban residents' per capita disposable income and the scale of third-party payment, that is, there is a long-term stable equilibrium relationship. With the improvement of China's urbanization level, the increasing population of urban residents and the popularity of third-party payment, it is of great significance to tap the consumption potential of urban residents.

\section{Suggestion}

By trying to build a model, it is found that the expansion of the scale of third-party payment is conducive to improving the growth of urban residents' clothing consumption, and puts forward the following suggestions: first, to effectively promote the growth of urban residents' consumption and promote residents to expand consumption, it is necessary to strengthen the supervision of the security mode of third-party payment and strengthen security technology and security guarantee. Second, we should not only ensure the safety of consumers' funds, but also constantly innovate the payment mode and payment market, establish a more perfect payment system, ensure the legitimate rights and interests of consumers while innovating, and finally better serve consumers. Third: improve the legal system, establish a national credit system, prevent malicious transactions and protect the legitimate rights and interests of both buyers and sellers. Enable residents to pursue high-quality development, rely on the domestic market to achieve economic development and create a good social atmosphere, so as to promote China to take the domestic big cycle as the main body, give full play to the super large-scale market advantages and domestic demand potential, help China expand domestic demand, promote the high-quality development of China's economy and achieve sustainable economic growth.

\section{Conclusion}

This paper analyzes the relationship between urban residents' clothing consumption expenditure, urban residents' per capita disposable income and the scale of third-party payment from 2004 to 2019. The results show that from 2004 to 2019 , there is a long-term and stable equilibrium relationship between urban residents' clothing consumption expenditure, urban residents' per capita disposable income and the scale of third-party payment. The per capita disposable income of urban residents and the scale of third-party payment have a positive impact on urban residents' clothing expenditure. The expansion of the scale of third-party payment is conducive to reducing transaction costs and promoting residents' consumption. Shortcomings of this paper: first, this paper takes the transaction scale of the third-party payment market collected by Research and prospective industry research institute as an indicator to measure the development level of macro third-party payment, which may not be representative and 
comprehensive. Second, it does not take into account the impact of different regions, environment and subjective factors on urban residents' clothing consumption. Third, affected by the epidemic situation in 2020, the data in 2020 are not analyzed. Future researchers can analyze it from the post epidemic era.

\section{Conflicts of Interest}

The authors declare no conflicts of interest regarding the publication of this paper.

\section{References}

An, N, \& Liu, X. M. (2021). Analysis on Influencing Factors of Consumption Level of Urban Residents in Shandong Province. Times Economic and Trade, 18, 29-31.

Chen, B. C., Li, Y. H., \& Liu, M. F. (2021). Analysis on Influencing Factors of Consumption of Urban Residents in Shaanxi Province. Modern Marketing (Next Ten Days), No. $4,72-73$.

Ge, N., Hao, Z. X., \& Zhang, K. X. (2020). Influencing Factors of Consumption Expenditure of Chinese Urban Residents. Wealth Era, No. 7, 131-132.

Hu, D. B., \& Wang, X. Y. (2017). Research on the Impact of Mobile Payment on Consumer Behavior: Based on the Comparison of Different Payment Methods. Consumer Economy, 33, 77-82.

Hua, Y. R., \& Yu, H. L. (2018). Analysis of Mobile Payment on College Students' Consumption. Financial Economy, No. 22, 30-32.

Lv, J. L. (2017). Empirical Study on the Impact of Internet Finance on Residents' Consumption-Taking the Garment Industry as an Example. Market Weekly (Theoretical Research), No. 12, 82-84.

Sun, M. R. (2016). Analysis of Chinese Residents' Textile and Clothing Consumption Based on in Come Level and Regional Distribution (pp. 34-36). Tianjin University of Technology.

Wen, Y. (2019). Analysis on Influencing Factors of Household Clothing Sales in China. Times Finance, No. 21, 99-100.

$\mathrm{Wu}, \mathrm{S}$. (2021). Research on the Impact of Third-Party Payment on Household Consumption Structure (pp. 64-67). Anhui University of Finance and Economics.

Xie, L. (2019). Empirical Study on the Impact of Third-Party Payment on Chinese Consumption (pp. 85-87). Southwest University of Finance and Economics.

Xing, T. C., \& Zhang, X. (2019). The Impact of Internet Consumer Finance on the Consumption Up-Grading and Consumption Tendency of Urban Residents. Contemporary Economic Research, No. 5, 61-63.

Zhang, S. R. (2020). Research on the Impact of Internet Finance on the Consumption of Urban Residents in China (pp. 45-48). Henan University.

Zhou, L. X. (2021). Research on the Impact of Third-Party Payment on Residents' Consumption in China (pp. 56-58). Jiangxi University of Finance and Economics. 